\title{
Correction to: The association of alcohol, cigarette, e-cigarette, and marijuana use with disease severity in adolescents and young adults with pediatric chronic kidney disease
}

\author{
Andrea R. Molino ${ }^{1}$ (D) J Judith Jerry-Fluker ${ }^{1} \cdot$ Meredith A. Atkinson $^{2} \cdot$ Susan L. Furth ${ }^{3} \cdot$ Bradley A. Warady $^{4}$. \\ Derek K. $\mathrm{Ng}^{1}$
}

Published online: 31 May 2021

(C) IPNA 2021

Correction to: Pediatric Nephrology

https://doi.org/10.1007/s00467-021-05044-5

The original version of this article unfortunately contained a mistake. Due to a technical error, an incorrect figure was used for Fig. 1. The corrected figure is given below. The original article has been corrected.

The online version of the original article can be found at https://doi.org/ 10.1007/s00467-021-05044-5

Derek K. Ng

dng@jhu.edu

1 Department of Epidemiology, Johns Hopkins Bloomberg School of Public Health, Baltimore, MD, USA

2 Department of Pediatrics, Johns Hopkins University School of Medicine, Baltimore, MD, USA

3 Department of Pediatrics, Division of Nephrology, The Children's Hospital of Philadelphia, Perelman School of Medicine at the University of Pennsylvania, Philadelphia, PA, USA

4 Department of Pediatrics, Division of Nephrology, Children's Mercy Kansas City, Kansas City, MO, USA 
eGFR (continuous)
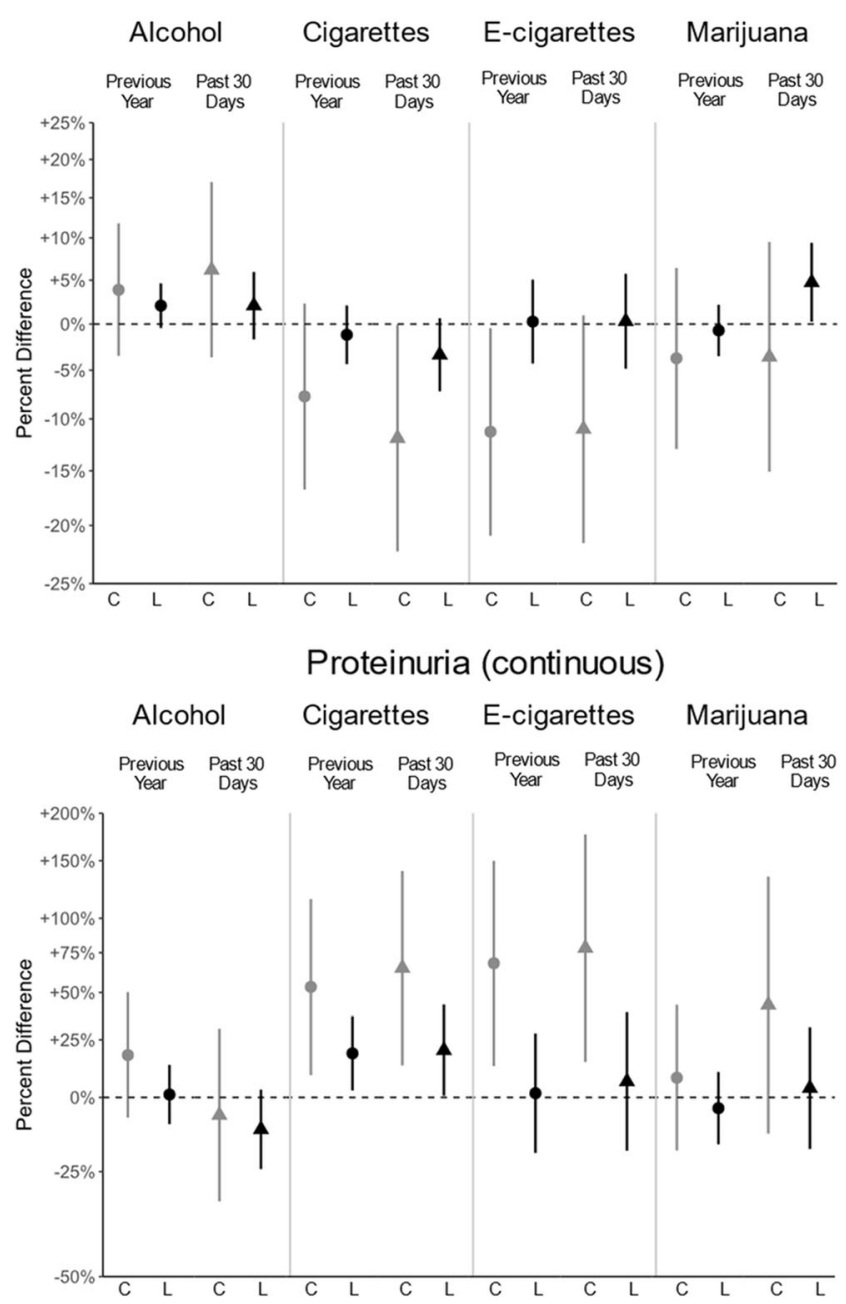

Fig. 1 Contemporaneous (C, gray) and lagged (L, black) model associations between previous year $(\bullet)$ and past 30-day ( $\boldsymbol{(})$ substance use as exposures and markers of kidney health as outcomes for those 16 years and older. Each substance and period of use was modeled separately. Estimates are presented as percent differences for eGFR and

Publisher's note Springer Nature remains neutral with regard to jurisdictional claims in published maps and institutional affiliations.

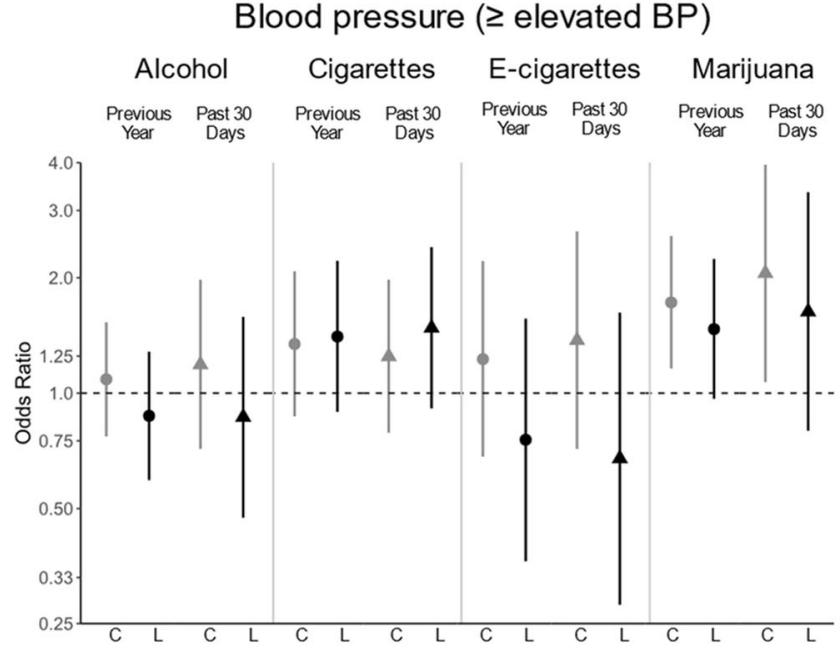

\section{Nephrotic range proteinuria ( $\mathrm{UPCR} \geq 2.0 \mathrm{mg} / \mathrm{mgCr}$ )}

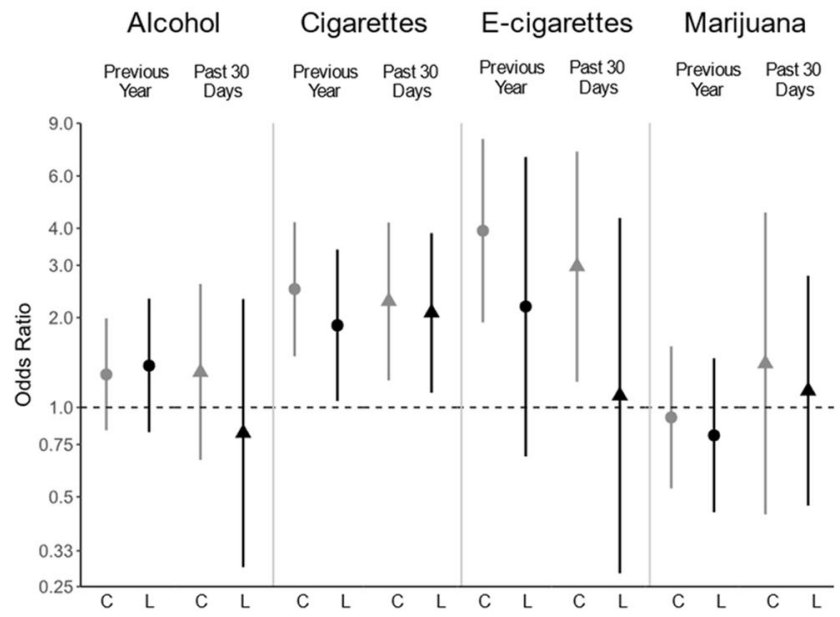

proteinuria, and relative odds for elevated blood pressure or higher (elevated BP, Stage 1 or Stage 2 hypertension) and nephrotic range proteinuria ( $\geq 2.0 \mathrm{mg} / \mathrm{mg}$ of creatinine), with $95 \%$ confidence interval bars 